\title{
Trocar Site Hernia after Use of an 8-mm Bladeless Trocar in Robotic Colorectal Surgery
}

\author{
Dae Ro Lim, M.D., Hyuk Hur, M.D., Byung Soh Min, M.D., Seung Hyuk Baik, M.D., Nam Kyu Kim, M.D. \\ Section of Colon and Rectal Surgery, Department of Surgery, Yonsei University College of Medicine, Seoul, Korea
}

Port site hernias are a rare complication after laparoscopic and robotic surgery. The current case is an 8-mm port site hernia which occurred after robot-assisted colorectal surgery. A 70-year-old female with a BMI (body mass index) of 25.7 was diagnosed as rectosigmoid colon cancer. She underwent a robot-assisted low anterior resection with double-stapled anastomosis for AJCC (American Joint Committee on Cancer) stage IIIB. After the main procedure, fascial defects in the supra-pubic and the supra-umbilical site were closed with a routine procedure $(12 \mathrm{~mm})$. Thirty two months after surgery, she developed an incisional hernia in the left mid abdomen (8-mm port). Recognition of the potential for a port site hernia using an 8- $\mathrm{mm}$ bladeless trocar port as well as a 12- $\mathrm{mm}$ port is essential in robotic surgery. Patients with risk factors for a port site hernia may require complete port site closure.

Keywords: Low anterior resection, Incisional hernia, Robotic surgery
Received September 8, 2015

Revised 1st October 12, 2015

2nd October 12, 2015

Accepted October 15, 2015

Corresponding author

Nam Kyu Kim

Section of Colon and Rectal Surgery, Department of Surgery, Yonsei University College of Medicine, Yeonseiro 50-1, Seodaemun-gu, Seoul 03722, Korea

Tel: +82-2-2228-2105

Fax: +82-2-313-8289

E-mail: namkyuk@yuhs.ac

This is an Open Access article distributed under the terms of the Creative Commons Attribution Non-Commercial License (http:// creativecommons.org/licenses/by-nc/4.0/) which permits unrestricted non-commercial use, distribution, and reproduction in any medium, provided the original work is properly cited.

\section{INTRODUCTION}

Port site hernias are a rare complication after laparoscopic and robotic surgery. Hernias at a port site less than $10 \mathrm{~mm}$ are a very rare complication. ${ }^{1}$ Tounichi et al. ${ }^{2}$ classified port site hernias into three groups according to the timing of presentation and the fascia defect involved. In the early-onset type, dehiscence of the anterior and posterior fascial layers as well as the peritoneum presents immediately post surgery and usually also presents with small bowel obstruction. These hernias require urgent surgical intervention and hernia site repair. Late-onset type refers to dehiscence of the anterior and posterior fascial layers alone, and hernias usually develop several months to years after surgery. These are not associated with small bowel obstruction and often present as a palpable abdominal swelling by the wound site. These hernias can be repaired in an elective surgery. Lastly, special type hernias refer to complete dehiscence of the abdominal wall and external evisceration of the peritoneal contents (intestine and/or omentum) without a hernia sac, usually occurring in the immediate postoperative period. These hernias require emergent surgery and immediate repair. The present case is an 8-mm port site hernia that occurred after robot-assisted colorectal surgery. According to the Tounichi classification of port site hernias, it is the late-onset type.

\section{CASE REPORT}

A 70-year-old woman with a body mass index of 25.7 was undergoing follow-up at an outpatient clinic after lower anterior resection for rectal cancer. She had no medical history and no operative history. She underwent a robot-assisted low 

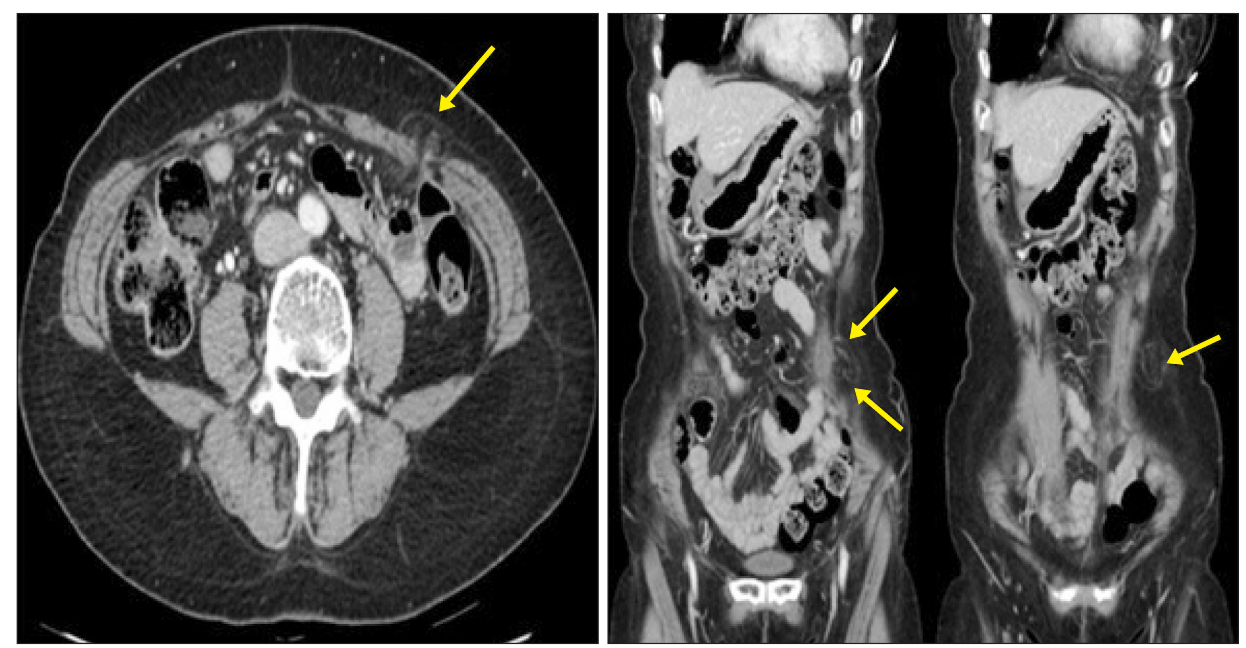

Fig. 1. Focal mesenteric fat hernia through the incision site in the left abdomen.

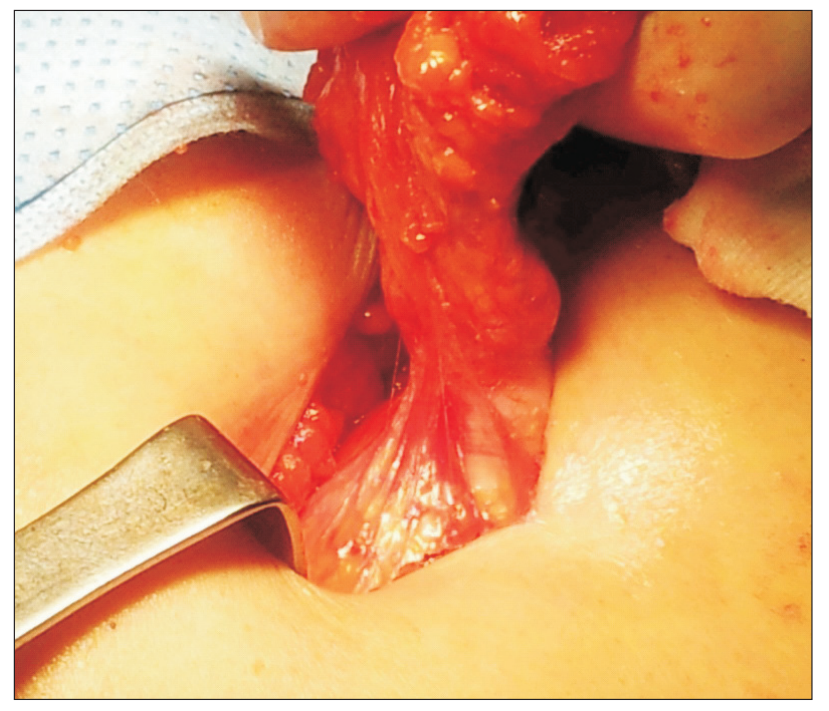

Fig. 2. Incisional hernia at the left mid abdomen; 8-mm trocar site and drainage tube used.

anterior resection with total mesorectal resection and doublestapled anastomosis for AJCC stage IIIB (pT3N1bM0) on April 2010. The procedure was completed with the 4-arm da Vinci Si Surgical System (Intuitive Surgical, Sunnydale, CA). After the main procedure, fascia defects of the 12-mm port in the supra-pubic area and the 12-mm port at the supra-umbilical site (camera port) were closed in a routine procedure. Other fascia defects of the 8-mm port and the 5-mm port were not closed. On the tenth postoperative day, she was discharged in a satisfactory condition. She then received $12^{\text {th }}$ oxaliplatin-based adjuvant chemotherapy. Thirty-two months after surgery, she developed an incisional hernia in the left mid abdomen at the site of the 8-mm port, which was also used for the drainage tube. She presented with abdominal pain, a palpable mass, and tenderness. CT scan showed a focal mesenteric fat hernia extruding through the incision site in the left abdomen (Fig. 1). She received elective surgery, in which the hernia sac was removed and the hernia was repaired (Fig. 2). She was discharged on the second postoperative day.

\section{Patient setup and port placement}

We used the following patient setup and port placement for robotic colorectal surgery. A $10-\mathrm{mm}$ trocar was placed through an incision approximately $3 \mathrm{~cm}$ above the umbilicus after achieving pneumoperitoneum. Next, a $30^{\circ}$ standard robotic laparoscope was inserted through the $10-\mathrm{mm}$ trocar. The first $8-\mathrm{mm}$ da Vinci ${ }^{\circledR}$ trocar was placed at a point twothirds of the distance between the supraumbilical $12-\mathrm{mm}$ trocar (camera port) and the right anterior superior iliac supine. The second 8-mm da Vinci ${ }^{\circledR}$ trocar was inserted $2 \mathrm{~cm}$ below and $2 \mathrm{~cm}$ to the left of the xiphoid process. The third 8-mm da Vinci ${ }^{\circledR}$ trocar was inserted at a point one-third of the distance between the camera port and the right anterior superior iliac supine. The fourth 8-mm trocar was placed in the left mid abdomen approximately $8 \mathrm{~cm}$ lateral to the umbilicus. The 12- $\mathrm{mm}$ trocar was placed $2 \mathrm{~cm}$ above and 2 $\mathrm{cm}$ to the right of the suprapubic area. The 5-mm trocar was placed in the right upper abdomen (Fig. 3).

\section{DISCUSSION}

The incidence of port site hernias is $1.47 \%$, occurring within an average follow-up period of 71.5 months after laparoscopic colorectal surgery. ${ }^{3}$ Lumley et al. ${ }^{4}$ reported port site hernia after laparoscopic colorectal surgery for cancer with an incidence of $0.55 \%$. Fuller et al. ${ }^{5}$ reported port site hernia after robot-assisted radical prostatectomy with an incidence of $4.8 \%$ 

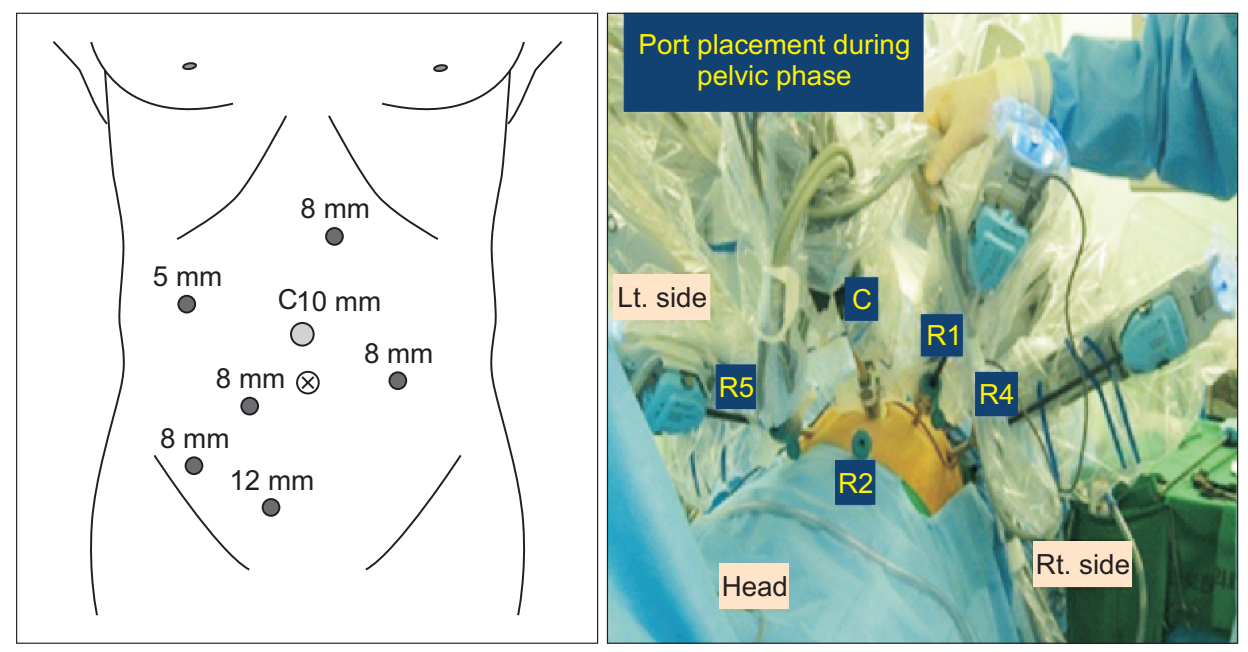

Fig. 3. Patient setup and port placement.

Table 1. Literature review of robotic trocar site hernias

\begin{tabular}{|c|c|c|c|c|c|c|c|}
\hline Author & Surgery & Incidence & $\begin{array}{l}\text { Number of } \\
\text { cases }\end{array}$ & Location of hernia & $\begin{array}{l}\text { Size of } \\
\text { trocar }\end{array}$ & Onset type & Contents \\
\hline $\begin{array}{l}\text { Seamon et al. } \\
(2008)^{8}\end{array}$ & $\begin{array}{l}\text { Gynecologic cancer } \\
\text { surgery }\end{array}$ & - & 1 & Left abdominal wall & $8 \mathrm{~mm}$ & Early & $\begin{array}{l}\text { Small bowel } \\
\text { evisceration }\end{array}$ \\
\hline $\begin{array}{l}\text { Matin et al. } \\
(2010)^{7}\end{array}$ & $\begin{array}{l}\text { Prostate cancer } \\
\text { surgery }\end{array}$ & $\begin{array}{c}0.66 \% \\
(7 / 1055)\end{array}$ & $\begin{array}{l}4 \text { case of } \\
\text { robotic }\end{array}$ & $\begin{array}{l}\text { Right lower quadrant } \\
\text { of the abdominal wall }\end{array}$ & $5,8, \& 12 \mathrm{~mm}$ & $\begin{array}{l}\text { Late (median, } \\
13 \text { months) }\end{array}$ & $\begin{array}{l}\text { Small bowel } \\
\text { incarceration \& } \\
\text { mesentery }\end{array}$ \\
\hline $\begin{array}{l}\text { Fuller et al. } \\
(2011)^{5}\end{array}$ & $\begin{array}{l}\text { Prostate cancer } \\
\text { surgery }\end{array}$ & $\begin{array}{c}4.8 \% \\
(12 / 250)\end{array}$ & 12 & $\begin{array}{l}\text { Midline and left } \\
\text { abdominal wall }\end{array}$ & $12 \& 8 \mathrm{~mm}$ & $\begin{array}{l}\text { Late (mean, } \\
14.8 \text { months) }\end{array}$ & $\begin{array}{l}\text { Small bowel } \\
\text { incarceration } 8 \\
\text { mesentery }\end{array}$ \\
\hline $\begin{array}{l}\text { Park MG et al. } \\
(2012)^{9}\end{array}$ & $\begin{array}{l}\text { Colorectal cancer } \\
\text { surgery }\end{array}$ & - & 1 & $\begin{array}{l}\text { Right lower quadrant } \\
\text { of the abdominal wall }\end{array}$ & $12 \mathrm{~mm}$ & Early & $\begin{array}{l}\text { Small bowel } \\
\text { incarceration }\end{array}$ \\
\hline $\begin{array}{l}\text { Kim IY et al. } \\
(2012)^{10}\end{array}$ & $\begin{array}{l}\text { Prostate cancer } \\
\text { surgery }\end{array}$ & $\begin{array}{c}0.4 \% \\
(2 / 498)\end{array}$ & 2 & $\begin{array}{l}\text { Supraumbilical } \\
\text { abdominal wall }\end{array}$ & $12 \mathrm{~mm}$ & $\begin{array}{l}\text { Late } \\
\text { (12/18 months) }\end{array}$ & Omentum \\
\hline Present case & $\begin{array}{l}\text { Colorectal cancer } \\
\text { surgery }\end{array}$ & $\begin{array}{l}0.54 \% \\
(2 / 370)\end{array}$ & 1 & Left abdominal wall & $8 \mathrm{~mm}$ & $\begin{array}{l}\text { Late } \\
\text { (32 months) }\end{array}$ & $\begin{array}{l}\text { Omentum \& } \\
\text { mesentery fat }\end{array}$ \\
\hline
\end{tabular}

(12/250 cases) during a follow-up period of 35 months. In the present study, the incidence of port site hernias after robotassisted rectal cancer surgery was $0.54 \%$ (2/370 cases) between January 2006 and December 2010, with a mean follow-up of 36.5 months (Table 1). There are several factors that affect port site hernias. These factors can be divided into two categories: patient factors and technical factors. Patient factors include nutritional status, chronic obstructive pulmonary disease, ${ }^{5}$ and diabetes. $^{6}$

Technical factors include placement of the port, size of the port, the presence of a port site defect closure, and manipulation of the port site.

The placement of ports is a risk factor for port site hernias.
Midline ports, particularly umbilical ports, are by far the most common sites for herniation after a laparoscopic procedure. ${ }^{3}$ Matin et al. reported six of seven patients with hernias in the right lower quadrant after laparoscopic or robotic urologic surgery. The patients in the present cases developed a port site hernia in the left lateral region.

The size of the port used is associated with a tendency to develop a port site hernia. A 1994 survey by the American Association of Gynecological Laparoscopists reported that 725 (86.3\%) of 840 hernias in which the size of the original defect were occurred at the sites of ports $10 \mathrm{~mm}$ in diameter or greater. Only 23 (2.7\%) patients had hernias that occurred in port sites smaller than $8 \mathrm{~mm}{ }^{1}$. Tounichi et al. ${ }^{2}$ reported $78.3 \%$ 
of port site hernias occurred at the 10 12 $\mathrm{mm}$ trocar site, while $21.7 \%$ occurred at the site of a trocar whose diameter was $\leq 5$ $\mathrm{mm}$. Unlike laparoscopic surgery, in robotic surgery, a trocar is mostly used with the $8-\mathrm{mm}$ port. Seamon et al. ${ }^{8}$ reported a case of small bowel obstruction after herniation through an 8-mm robotic port defect at the left mid abdomen after robotic gynecologic cancer surgery. Fuller et al. ${ }^{5}$ reported that 10 of 12 patients had trocar site hernias at the 12-mm umbilical port site, and one patient had a hernia at the left lateral $8-\mathrm{mm}$ port site after robot-assisted radical prostatectomy. The 8-mm port site was used occasionally for the wound drainage tube insertion site, and herniation at this site occurred in association with removal of the wound drainage tube. The present case was a left lateral 8-mm port site hernia, which was the site also used for the wound drainage tube.

Whether to close the port site defect or leave it open is still controversial. Most surgeons have advised fascial closure for trocar sites greater than $10 \mathrm{~mm}$ due to literature reporting incidence. Sanz-Lopez et al. ${ }^{6}$ recommended routine fascial closure for laparoscopic port sites greater than $5 \mathrm{~mm}$ and for all defects in children regardless of size.

Manipulation of the trocar port site may widen a port site incision. Multiple reinsertions of the trocar and advanced surgical difficulty requiring increased force and torque on the fascia can also widen the initial port site. The robotic arm moves around a fixed pivoting point through the 8-mm port site. If the pivot point of the robotic port is inadequately distanced from the fascial layer, the robotic arm can damage the fascia around the port site because of its constant large motion and force. The robotic arms are prone to creating larger fascial defects due to the inadequate location of the robotic port. Because of that, the pivoting point is painted on the tip of the robotic port, surgeon should check whether the pivoting point is at the adequate position. In addition force of torque of robotic arms is strong and range of motion is wide. In these reasons, we think that potentialities of trocar site herniation development are higher by using robotic arm at same size small trocar site comparing by using other instrument such like laparoscopic device. The reason is that robotic arms have more large torque and range of motion than laparoscopic instrument. Based on our incidence data, we think that routine closure of fascial defects of the 8-mm port site is not necessary; however, if operations require reinsertion of the trocar, a longer operation time, or excessive motion and traction of the robotic arm during surgery, surgeons should check the fascial defect and closure of the port site. Due to force of torque of robotic arms is strong and range of motion is wider, defect size of $8 \mathrm{~mm}$ trocar site could become more than $12 \mathrm{~mm}$ defect size at finishing operation time. And then it will be occurred hernia through this defect site widening more, if missed the shift which surgeon did not check. In conclusion, recognition of the potential for port site herniation using an $8-\mathrm{mm}$ bladeless trocar port as well as a $12-\mathrm{mm}$ trocar port is essential in robotic surgery. If a patient has risk factors, port site closure may be necessary.

\section{REFERENCES}

1) Montz FJ, Holschneider $\mathrm{CH}$, Munro MG. Incisional hernia following laparoscopy: a survey of the American Association of Gynecologic Laparoscopists. Obstet Gynecol 1994;84:881-884.

2) Tonouchi H, Ohmori Y, Kobayaschi, Kusunoki M. Trocar site hernia. Arch Surg 2004;139:1248-1256.

3) Owens M, Barry M, Januua AZ, Winter DC. A systemic review of laparoscopic port site hernias in gastrointestinal surgery. The Surgeon 2011;9:218-924.

4) Lumley J, Stitz R, Stevenson A, Fielding G, Luck A. Laparoscopic colorectal surgery for cancer: intermediate to long-term outcomes. Dis Colon Rectum 2002;45:867-872.

5) Fuller A, Fernandez A, Pautler SD. Incisional hernia after robotassisted radical prostatectomy predisposing factors in a prospective cohort of 250 cases. Journal of Endourology 2011;24:1021-1024.

6) Sanz-Lopez R, Martinez-Ramos C, Nunez-Pena JR, Ruiz de Gopegui M, Pastor-Sirera L, Tamames-Escobar S. Incisional hernias after laparoscopic vs open cholecystectomy. Surg Endosc 1999;13:922-924.

7) Chiong E, Hegarty PK, Davis JW, Kamat AM, Pisters LL, Martin SF. Port-site hernias occurring after the use of bladeless radially expanding trocars. Urology 2010;75:574-580.

8) Seamon LG, Backes DF, Resnick K, Cohn DE. Robotic trocar site small bowel evisceration after gynecologic cancer surgery. Obstet Gynecol 2008;112:462-4.

9) Park MG, Kang JK, Kim JY, Hur H, Min BS, Lee KY, Kim NK. Trocar site hernia after the use of $12-\mathrm{mm}$ bladeless trocar in robotic colorectal surgery. Surg Laparosc Endo Percutan Tech 2012;22:34-36.

10) Kang DI, Woo SH, Lee DH, Kim IY. Incidence of port site hernias after robot assisted radical prostatectomy with the fascial closure of only the midline 12-mm port site. Journal of endourology 2012; 26:848-851. 